\title{
The Effect of Three Instructional Elements on Achievement in Computer-Based Mathematics Instructions of Senior Secondary School Students in Nigeria
}

\author{
Tayo Omoniyi, Ph.D \\ Science and Technology Education Department \\ Faculty of Education, Olabisi Onabanjo University \\ P.M.B. 2002, Ago-Iwoye, Ogun State, Nigeria \\ Gisanrin Gbenga, M.Ed
}

Babcock University High School, Ilishan, Ogun State, Nigeria

Doi: 10.1515/ajis-2017-0001

\begin{abstract}
This study investigated the effect of three instructional elements on achievement in computer-based mathematics instructions. The subjects were senior secondary school students who used four versions of computer-based instructions developed on compact disc to learn about volume of solid shapes. The four versions of the programme were (1) a full version that had the three instructional elements (2) a version without objective (3) a version without practice (4) a version without examples. Results indicated that the full package, which included objective, practice and examples, had significant effect on students' achievement in the computer-based mathematics instructions. Furthermore, of the three elements, practice, had the most effect on the learners' achievement. Implications of the findings on development of computer-based instructions are also discussed.
\end{abstract}

Keywords: Computer-based Instruction, Mathematics education, Instructional elements, Students' achievement

\section{Introduction}

Information Communication Technology has become a significant factor in the way we learn, communicate, govern ourselves and do business. Indeed, Information Communication Technology (ICT) is a driving factor in the process of globalization. ICTs have revolutionized the teaching and learning process by increasing access through the use of a great variety of educational resources and enabling participatory pedagogies. The use of ICTs in education provides the learners with a more suitable environment to learn, serves to create interest and a learner-centred atmosphere, and helps to increase student's motivation (Serin, 2011).

Computer Based Instruction (CBI) is an example of how Information Communication Technologies are integrated into the teaching and learning process. A pedagogical technique that is computer driven is defined as Computer Based Instruction. As most modern Information Communication Technologies are computer driven, ICT's utilization in teaching and learning process is often defined as Computer Based Instruction. The use of CBI helps students to process and develop information, take active part in the learning process and develop their problem solving skills. According to Chang (2002), computer-based instruction is far more effective than the traditional teaching methods, as it is effective in presenting information, testing, evaluating and providing immediate feedback. 
$\mathrm{CBI}$ enables learners to progress at their own pace and provides them with appropriate alternative ways of learning by individualizing the learning process (Senemoglu, 2003). As a multimedia approach to instruction, CBI provides drawings, graphics, animation, music and other varieties that make its lesson presentations very exciting to learners, particularly because by utilizing this multi-media approach, abstract concepts are concretized for ease of understanding.

\subsection{Theoretical Framework}

The theoretical basis of this study is Criterion Reference Instruction (CRI) developed by Robert Mager, a behaviorist. The theory is a comprehensive set of steps for design and delivery of instructional programme. The concept makes learning self-instructional. Some of the critical aspects of the theory according to Mager (1988) include:

1. Task Analysis: This requires identification of what needs to be learned, a need assessment level.

2. Performance Objectives: Specification of Instructional outcomes i.e what are to be accomplished and how they are to be evaluated (the criterion).

3. Criterion Referenced Testing: Evaluation of learning outcomes, in terms of knowledge specified in the performance objectives.

4. Modules: Development of learning modules relating to specific objectives

CRI is based on ideas of mastery learning. It also incorporates many ideas of Gagne's conditions of learning, including task hierarchies. The major contribution of Criterion Reference Instruction to programmed instruction, including computer based instruction, is the stress on formation of objectives in a clear and specific manner before progressing to organize instructions.

According to Owusu, Monney, Appiah and Wilmot, (2010), the use of computer assisted instruction especially in tutorial mode is supported mostly by the behaviourist's view of learning, largely due to the principles of objective, practice and reinforcement.

This study made use of the criterion referenced instruction, derived from the practices of Robert Mager's behaviorism. The activities were presented in graded steps as recommended in task analysis. The students had the opportunity of being active in the learning process, and receiving immediate feedback. Students also worked at their own pace. The critical guide derived from the work of Robert Mager and other behaviorists is that elements of instruction are expected to be incorporated into any version of instructional programme, computer-based instruction inclusive. The elements that were directly incorporated into this study were objectives, examples and practice. Reviewed literature on each of the elements are presented below. It must be noted that instruction, though not manipulated, was a component of all the versions of this programme.

\subsection{Objectives}

An Instructional objective is a statement that describes what learners are expected to do or be able to do once the process of classroom instruction is over. According to Mager (1988), instructional objectives are best described in terms of the terminal behaviour expected form the learners. It describes the intended outcome of an instruction in behavioural (measurable) terms.

Studies have reported that when students know what will be expected of them, they tend to perform better. For instance, research on effectiveness of objectives in computer-based cooperative learning reported that students who were exposed to the instructional objectives performed significantly better on posttest items than those who received either advanced organizers or no orientation activities (Klien \& Cavalier, 1999), Researchers have also found that objectives do not produce significant difference in learning (Martin, Klien \& Sullivan 2007). Hannafin (1987) reported that the presence of objectives systematically introduced into a computer-based instruction did not significantly influence performance in lessons presented.

\subsection{Instruction}

Instruction describes detailed information or directive on how something should be done or 
processed. According to Forcier and Descy (2002), every learning environment has an implied method of information presentation. Instruction also refers to the process or act of imparting knowledge. During the process of instruction, students encounter the content to be learnt, either in the didactic form or through a process of discovery (Martins et al, 2007).

In computer-based instruction, instruction includes processes for presenting educational information to students. The teacher or instructional designer frames such information, rules or principles to guide exploration of the material by the students. Such instructions aimed at aiding the tasks stated in the $\mathrm{CBI}$ objectives are explicitly presented.

\subsection{Practice}

Practice is defined as the event of instruction provided to learners after they have been given information required to achieve an objective (Gagne, 1988). Practice involves asking learners to perform given tasks. In computer-based instruction, practice provides a feedback on learners' understanding of concepts taught and reinforces retention.

Studies have reported that practice significantly affect academic achievement. Philips, Hannafin and Tripp (1988) found a significant difference favouring practice over no practice in an interactive video in which practice items were embedded questions. Yeo and Neal (2004) examined the relationship between motivation and performance during skill acquisition practice. It was reported that the relationship between effort and performance increased with practice.

\subsection{Examples}

Examples are verbal or graphical information that provides additional clarification of rules and information presented to leaners. Examples, graphical representation and analogies are some of the guidance strategies used in clarifying content in computer-based instructions. According to Sweller, Krischner and Clark (2007), worked example is so significant in academic achievement that it is rated the best known and widely studied of the elements regarding cognitive load effects. Worked example is said to improve learning by reducing cognitive load during skill acquisition.

\subsection{Purpose of the study}

The wide use of computer-based instructional packages, particularly in contemporary time, requires that elements of instructional design are included in their development. Most studies had examined single instructional element for effect, although a few had combined the elements. In general, studies have reported that presence of these elements resulted into positive effects on student learning outcomes. It is pertinent to examine the likely outcome of a combination of these elements in a programme on academic achievement of students in Nigerian secondary schools, with their infrastructural deficiency for the use of such technologies.

Therefore, this study examined the effect of objectives, examples and practices when they are systematically combined in a computer-based instruction. The question which guided this study was "which of the instructional elements investigated in this study significantly affected achievement?".

\section{Methodology}

\subsection{Research Design}

This quasi-experimental study used the pretest/posttest control group design. The mixed design is one of the most widely used designs in experimental studies.

\subsection{Sample}

The participants were 60 senior secondary school one (SSI) students. Purposive sampling technique was adopted in selecting the sixty participants from SS1 mathematics classes, of four (4) 
senior secondary schools in Ikenne and ljebu-Ode local government areas of Ogun State, Nigeria. The participants were of secondary schools with functional, well equipped computer laboratories and fair background knowledge of computer usage.

\subsection{Instruments}

Computer-based instructions $(\mathrm{CBI})$ on the next topic in mathematics, as detailed in the class. Scheme of work i.e. "volume of solid shapes", were developed. An introduction section was included in the programme and operations of the CBI explained in details.

Subsequent sections introduced the concept i.e. the other four sections described formulae for surface area and volume of solids, such as cuboids, prism, pyramid, cone, cylinder and sphere. Examples and related exercises were also included. The CBI was pilot tested with fifteen students of a secondary school which did not participate in the main study.

The material was designed in four different versions that included combinations of the elements. The four versions consisted of (1.) A programme with objective, practice and example (2.) A programme without objective (3) a programme without examples (4) a programme without practice.

The instrument for the study "Computer-Based Instruction Test" (CBIT) consisted of 30 objective items. Content was drawn from field validated past questions of the West African Senior Secondary School Mathematics Examination, 2001-2008.

\subsection{Validation}

To ascertain reliability of the adapted instrument, a draft of initial fifty (50) items was administered on fifteen students of a senior secondary school (SS1), different from the participating schools.

From the response of the students, discrimination and difficulty index was used to remove twenty of the items. Eventually, thirty (30) items consisted content of the CBIT.

A test retest technique was adopted to elicit data for reliability of the instrument. Kuder Richardon 20 (KR-20) was used to determine the reliability coefficient of the instrument, which was found to be 0.72 , the CBIT was administered as pretest. The posttest consisted of reshuffled version of the same 30 - item test.

The next topic in the scheme of work (volume of solid shapes) was selected and lesson prepared on four compact discs of thirty modules each, 10 modules per lesson. Copies of the disc were made and individual student interacted with the disc, using assigned computer in the laboratory, under the guidance of trained assistants who functioned as facilitators.

Participants in each school were given copies of a version of the computer-based instruction relating to the group they had been randomly assigned i.e. full package, without objective, without example and without practice. All the four groups followed the same procedure as detailed in the information provided as preamble to the content of the CBI.

At the end of the three weeks of treatment, the four groups were administered the CBIT, earlier used as pretest.

\subsection{Data Analysis}

Data were preliminary analyzed using descriptive statistics, while Analysis of covariance (ANCOVA) was used to analyze the data for statistical difference. 


\section{Results}

\subsection{Preliminary Analysis of Data}

Table 1: Descriptive Statistics of Students' Achievement in Computer-Based Instructions

\begin{tabular}{lccc}
\hline Treatment & Mean & Std. Deviation & $\mathrm{N}$ \\
\hline Full Package & 21.0667 & 3.88158 & 15 \\
Without Example & 17.8000 & 2.39643 & 15 \\
Without Objective & 19.8667 & 2.35635 & 15 \\
Without Practice & 17.4000 & 1.18322 & 15 \\
Total & 19.0333 & 2.97997 & 60 \\
\hline
\end{tabular}

The results in table 1 revealed that participants in the full package group had a mean score of 21.0667 with a standard deviation of 3.88158 whereas participants in the group without example had a mean score of 17.8000 with a standard deviation of 2.39643. Participants in the group without objective had a mean score of 19.8667 and a standard deviation of 2.35635 while participants in the group without practice had a mean score of 17.4000 with a standard deviation of 1.18322.

Table 2: Test of Between-subject Effects of Achievement in Students' Achievement in ComputerBased Instructions

\begin{tabular}{lccccc}
\hline Source & Type III Sum of Squares & df & Mean Square & F & Sig. \\
\hline Corrected Model & $314.663^{\mathrm{a}}$ & 4 & 78.666 & 20.675 & .000 \\
Intercept & 226.100 & 1 & 226.100 & 59.423 & .000 \\
pretest & 179.397 & 1 & 179.397 & 47.149 & .000 \\
Treatment group & 86.823 & 3 & 28.941 & 7.606 & .000 \\
Error & 209.270 & 55 & 3.805 & & \\
Total & 22260.000 & 60 & & & \\
Corrected Total & 523.933 & 59 & & & \\
\hline
\end{tabular}

a. R Squared $=.601$ (Adjusted R Squared $=.572$ )

b. Covariates appearing in the model are evaluated at the following values: pre-test $=15.5667$.

The results in Table 2 indicated that there was a significant effect of the three instructional elements on students' achievement in computer-based instructions $\left(F_{(3,55)}=7.606 ; p<.05\right)$. The hypothesis which stated that there is no significant effect of three instructional elements on students' achievement in computer-based instructions was rejected by the finding of this study. The implication of the finding was that instructing students with the three instructional elements will significantly impact on their achievement in computer-based instructions.

Table 3: Test of Between-subject Effects of Achievement in Students' Achievement in ComputerBased Instructions

\begin{tabular}{|c|c|c|c|c|c|c|}
\hline \multirow[t]{2}{*}{ (I) treatment } & \multirow[t]{2}{*}{ (J) treatment } & \multirow{2}{*}{$\begin{array}{c}\text { Mean } \\
\text { Difference } \\
(\mathrm{I}-\mathrm{J})\end{array}$} & \multirow{2}{*}{\multicolumn{2}{|c|}{ Std. Error Sig. ${ }^{b}$}} & \multicolumn{2}{|c|}{$\begin{array}{l}\text { 95\% Confidence Interval for } \\
\text { Difference }^{b}\end{array}$} \\
\hline & & & & & Lower Bound & Upper Bound \\
\hline & Without Example & $2.278^{\circ}$ & .727 & .017 & 289 & $4.267^{\circ}$ \\
\hline \multirow{3}{*}{ Full Package } & Without Objective & .630 & .717 & 1.000 & -1.333 & 2.592 \\
\hline & Without Practice & $3.020^{\pi}$ & .718 & .001 & 1.054 & $4.987^{\pi}$ \\
\hline & Full Package & $-2.278^{*}$ & .727 & .017 & -4.267 & $-.289^{*}$ \\
\hline \multirow[t]{3}{*}{ Without Example } & Without Objective & -1.648 & .715 & .149 & -3.605 & .308 \\
\hline & Without Practice & .742 & .714 & 1.000 & -1.212 & 2.696 \\
\hline & Full Package & -.630 & .717 & 1.000 & -2.592 & 1.333 \\
\hline \multirow[t]{3}{*}{ Without Objective } & Without Example & 1.648 & .715 & .149 & -.308 & 3.605 \\
\hline & Without Practice & $2.391^{*}$ & .712 & .009 & .441 & $4.340^{*}$ \\
\hline & Full Package & $-3.020^{*}$ & .718 & .001 & -4.987 & $-1.054^{*}$ \\
\hline \multirow[t]{2}{*}{ Without Practice } & Without Example & -.742 & .714 & 1.000 & -2.696 & 1.212 \\
\hline & Without Objective & $-2.391^{*}$ & .712 & .009 & -4.340 & $-.441^{*}$ \\
\hline
\end{tabular}

Based on estimated marginal means; ${ }^{*}$. The mean difference is significant at the .05 level.

b. Adjustment for multiple comparisons: Bonferroni. 
Results in Table 3 showed that full package had a significant effect on students' achievement in computer-based instructions over and above those in the group without example (MD $=2.278$; std error $=.727 ; p<.05)$. Also full package had a significant effect on students' achievement in computer-based instructions over and above those in the group without practice (MD $=3.020$; std error $=.718 ; p<.05)$. Again, the package without objective had a significant effect on students' achievement in computer-based instructions over and above those in the group without practice $(M D=2.391 ;$ std error $=.712 ; p<.05)$. in effect, withdrawing the elements of objective, practice and example from instructional package have detrimental effects on students' achievement in computer-based instructions. Withdrawing the element of practice was however more detrimental on students' achievement in computer-based instructions than withdrawing the element of example. The results are as graphically illustrated in Figure 1

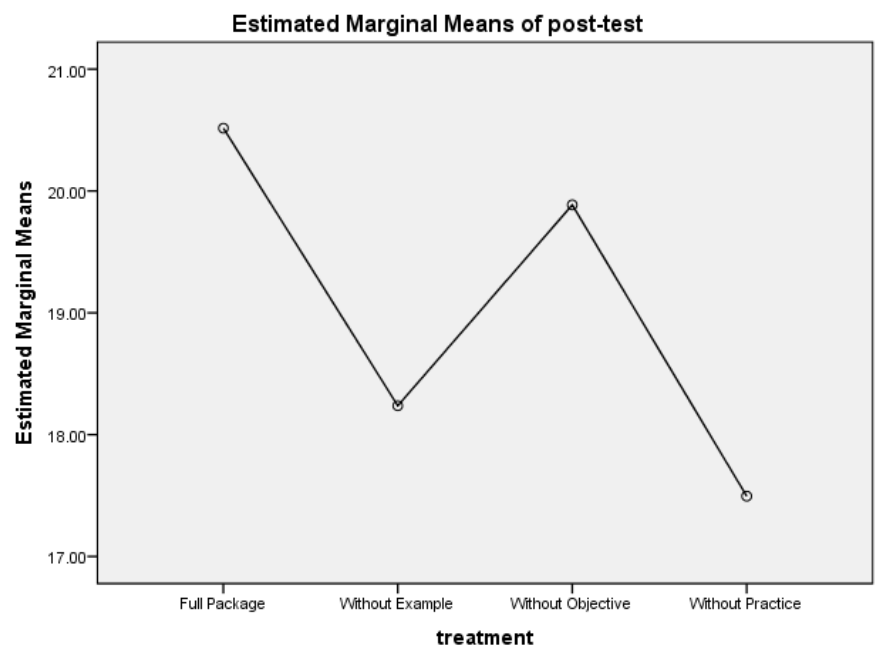

Covariates appearing in the model are evaluated at the following values: pre-test $=15.5667$

\section{Discussion and Recommendations}

This study examined the effect of three instructional elements (examples, objective \& practice) on achievement in secondary school mathematics. Instructions were stored on compact disc and copies made for students to access and study, using computers in the schools' laboratories.

Results indicated that the full package which included the three elements (objective, practice \& example) had significant effect on students' achievement in the computer-based mathematics instructions when compared with those in the groups without example, objective and practice. This finding is in agreement with the result of a similar study (Serin, 2011) which reported that computerbased instruction significantly increased students' achievement and problem solving skills in science and technology. The finding is also in agreement with the results of similar studies reported by Martin, Klein and Sullivan (2007); Dogan (2010). Furthermore, practice had the most effect on the learners achievement, as participants who had exposure to a version of the computerbased instructions that included practice performed significantly better on the posttest than the group with a version that excluded practice. The exclusion of the two elements (object \& examples) did not have such an effect.

Typical of self-instructional package, practice in this study allowed for feedback to learners' response, this is aside the opportunity provided learners to do task similar to the one being assessed. Findings also indicated that each of the instructional elements had significant effect on students' achievement in this study. However, example is another element that its withdrawal affected students' achievement quite significantly. 
The findings have implications on design and development of computer-based instructions. Although only three elements of instruction (objective, examples \& practice) had their effect investigated in this study, it does not imply that the other elements such as information and review are less important. However, it is being recommended that the three elements examined for effect must be included in the design and development of computer-based instructions. Similarly, the potentials of practice as an element with significant impact must be maximally explored in the design of $\mathrm{CBI}$.

This study was carried out in Nigeria, a developing Nation, with weak infrastructural base for the use of computer-based instructions, including erratic power supply. This explains why the instructions had to be developed using compact disc, not the web, as done by most other similar studies. It is important to stress this peculiarity of developing countries to appreciate their limitations in the use of computer-based instructions. It therefore implies that this study may be replicated in Nigeria and other developing countries when such instructions are web-based. Further research may also include the instructional elements such as information and review. Attitude of students to web-based instructions and computer-based instruction stored on compact disc could also be investigated, particularly in Africa and other developing countries where such studies could assist instruction designers.

\section{References}

Chang, C. Y. (2002). Does computer-assisted instruction, problem solving improve science outcomes? A pioneer study. The journal of Education Research, 95 (3), 143-150.

Dogan, N. (2010). The effect of computer assisted statistics instruction on achievements and attitudes toward statistics. Education and Science, 34 (154), 3-16

Forcier, R.C \& Descy, D.E (2002). The computer as an educational tool (3 ${ }^{\text {rd }}$ ed). Upper Saddle River. NJ: Merrill/Prentice Hall.

Gisanrin, Gbenga, (2011). Impact of three instructional elements on students achievement in computer-based instructions. An M.Ed Dissertation submitted to the Department of Curriculum Studies and Instructional Technology, Olabisi Onabanjo University, Ago-Iwoye, Nigeria.

Hannafin, M. (1987). The effects of orienting activities, cueing and practice or learning of computer-based instruction. Journal of Educational Research, 81 (1), 48-53.

Klein, J.D. \& Cavalier, J.C. (1999). Using Cooperative learning and objectives with computer-based Instruction. Paper presented at the Annual convention of the Association for Educational Communications and Technology. Houston, Texas.

Mager, Robert. (1988). Making Instruction work. Belmont, C.A. Lake Publishing Co.

Martin, F., Klien, J.D. \& Sullivan, H (2007). The impact of instructional elements in computer-based instruction. British Journal of Educational, Technology. 38 (4) 623-636.

Owusu, K.A., Money, K. A., Appiah, J.Y., \& Wilmot, E.M. (2010). Effects of computer-assisted instruction on performance of senior high school biology students in Ghana. Computer \& Education. 55, 904-910.

Philips, t., Hannafin, M \& Trip, S. (1988). The effects of practice and orienting activities on learning from interactive video. Educational Communication and Technology Journal. 36, 93-102

Senemoglu, N. (2003). Development learning and teaching. Ankara: Gazi Publishing.

Serin, O. (2011). The effects of the computer-based Instruction on the achievement and problem solving skills of the science and Technology students. The Torkish Journal of Educational Technology. 10 (1), 183-199

Sweller, John., Krischner, Paul. A., \& Clark, Richard, E. (2007). Why minimally Guided Teaching Techniques do not work Educational Psychologist, 42 (2) 115-121 